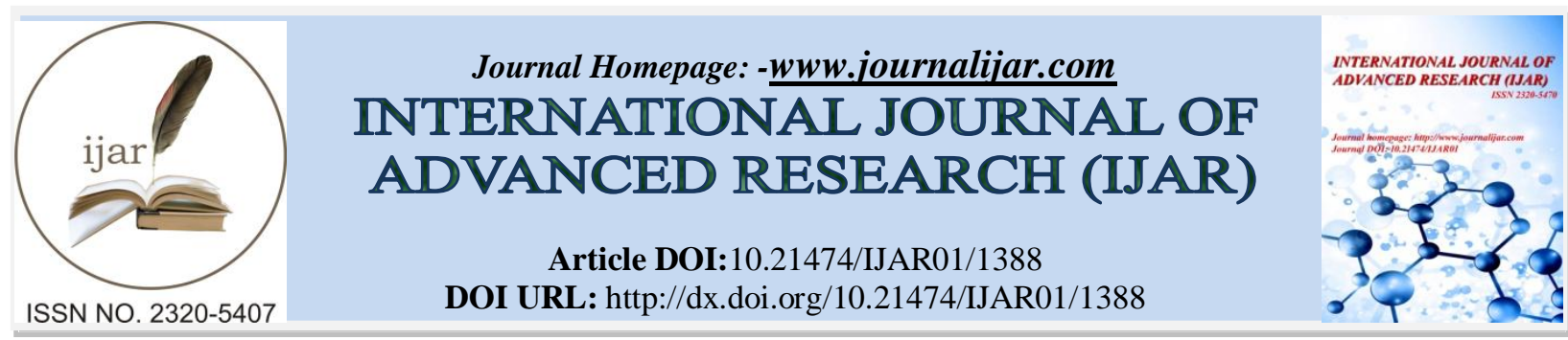

RESEARCH ARTICLE

\title{
THE RELATIONSHIP BETWEEN THE SOLUBLE AND EXCHANGEABLE MAGNESIUM IN NILE DELTA SOILS.
}

\author{
Abou El-Soud, M.A., Gazia, E.A. E, Amer, M.M. and Aboelsoud, H.M. \\ Soils, Water \& Environment Research Institute, Agric. Res. Centre (ARC), Giza, Egypt.
}

\section{Manuscript Info}

Manuscript History

Received: 15 June 2016

Final Accepted: 16 July 2016

Published: August 2016

Key words:-

Magnesium to calcium ratio, exchangeable magnesium percentage, magnesium-rich soil.

\section{Abstract}

Salt affected soils exist in several parts of Nile Delta of which are high-magnesium soils with improper properties. The identifying of rich-magnesium soils requires estimation ofthe exchangeable magnesium percentage $(\mathrm{EMgP})$ and/or the exchangeable magnesium to exchangeable calcium ratio $(\mathrm{EMg} / \mathrm{ECa})$. The $\mathrm{EMgP}$ value and $\mathrm{EMg} / \mathrm{ECa}$ ratio on soil surface are important statements that have an obvious equilibrium with the relative values of $\mathrm{Mg}$ and $\mathrm{Ca}$ in soil solution. Preliminary study was carried out to create proper relationship between the soluble magnesium in soil solution and exchangeable magnesium on the exchange complexes in Nile Delta soils.

To derive the relations between both soluble and exchangeable magnesium in soil, 90 soil samples were collected during winter season (2015/2016) from Kafre El-Sheikh, El-Hamoul, Borollus, Motobus and El-Mahalla Districts to represent non saline-, medium saline- and high saline- soils. The soluble cations in soil paste extract and the exchangeable cations on soil surface were determined. Chemical analysis of soil paste extract showed that the soluble magnesium percentage $(\mathrm{SMgP})$ ranged from 9.0 to 36 and $\mathrm{SMg} / \mathrm{SCa}$ ratio in soil solution ranged from 0.2 to 3.5. The determination of the exchangeable cations on soil surface indicated that EMgP value ranged from 8 to 29 and $\mathrm{EMg} / \mathrm{ECa}$ ratio ranged from 0.12 to 2.0. Three empirical equations were derived to represent the relationships between:

\section{1- SMg/SCavs. EMg/ECa:}

$\mathrm{EMg} / \mathrm{ECa}=-0.245+1.362(\mathrm{SMg} / \mathrm{SCa})-0.246(\mathrm{SMg} / \mathrm{SCa})^{2}$

2- SMgPvs. EMgP:

$$
\left(\mathrm{R}^{2}=0.858\right) \quad(1)
$$

$\mathrm{EMgP}=-9.298+2.191(\mathrm{SMgP})-0.032(\mathrm{SMgP})^{2}\left(\mathrm{R}^{2}=0.817\right)$

3- SMgP vs. EMgP after the suitable transformation:

$\mathrm{EMgP}=-0.432+3.098(\mathrm{ASIN}(\mathrm{SQRT}(\mathrm{SMgP} / 100))-2.438(\mathrm{SQRT}$

$$
(\mathrm{SMgP} / 100))^{2}(3)\left(\mathrm{R}^{2}=0.830\right)
$$

The coefficients of determination for the obtained relations aremost proper; consequently, $\mathrm{EMg} / \mathrm{ECa}$ ratio and $\mathrm{EMgP}$ valueon soil surface can be safely predicted from their values in soil solution using these equations.

Corresponding Author: -Abou El-Soud. 


\section{Introduction:-}

Salt affected soils exist in several parts of Nile Delta of which are high-magnesium soils with improper properties. To characterizethe rich-magnesium soils, the exchangeable magnesium percentage (EMgP) and/or the exchangeable magnesium to exchangeable calcium ratio $(\mathrm{EMg} / \mathrm{ECa})$ are required to be estimated. A possible reason for a specific $\mathrm{Mg}$ effect is that the hydration energy of $\mathrm{Mg}$ is greater than that of $\mathrm{Ca}$, and the hydration radius is also greater , 0.47 vs. $0.42 \mathrm{~nm}$ (Bohn et al., 1985), consequently lower electro static force with which a hydrated $\mathrm{Mg}$ ion is held at the clay surface(Curtin et al., 1994). Therefore, when sodium's relative flocculating power is 1, potassium's is 1.7, magnesium's is 27, and calcium's is the highest, at 43(Fisher, Madeline, 2011).

There is a lack of information about the effects of $\mathrm{Mg}$ on soils properties, type and source of compounds responsible for the Mg enrichment and the way this accumulation occurs. However, Dontsova and Norton (2002) reported that $\mathrm{Mg}$ has a specific effect on soil clay dispersion and infiltrations due to its hydration behavior and it has greater aggregate destruction than Ca. Agar (2012) added that magnesium has a negative effect on soil physical properties when its concentration is relatively high compared to Ca. Garcia-Ocampo (2003) reported that the accumulations of $+2$

$\mathrm{Mg}$ on soil exchange complex to a very high saturation levels affect their physical, chemical and biological properties depending on its saturation in the exchange complex and high hydration energy. Although , $\mathrm{Mg}$ is a divalent cation, its elevated levels on soil exchange sites to more than $25 \%$ result in severe structural degradation that leads to lower infiltration rate, hydraulic conductivity, structural instability (Vyshpolskyetal ,2015), lower permeability and more clay dispersion (Zhang and Norton ,2002). Also, the permeability tends to decrease with increasing $\mathrm{EMgP}($ Shainberg et al., 1988), while the dispersion of clays from soils was increased while the hydraulic conductivity was significantly reduced when $\mathrm{Ca} / \mathrm{Mg}$ ratios in the percolating solutions were below unity with an $\mathrm{SAR}_{1: 5}>3$.It was observed that the saturated hydraulic conductivities were $0.17,0.56$ and $1.84 \mathrm{~cm} \mathrm{~h}^{-1}$ with Ca/Mg ratios of 1:2, 1.5:2 and 1:1, respectively (Bardhan et al.,2007) while the productivity of soil was higher when $\mathrm{Ca} / \mathrm{Mg}$ ratio on the soil exchange complex was 3.2:1(Ansari et al.,2010).

Some researchers think that the $\mathrm{EMgP}$ value and $\mathrm{EMg} / \mathrm{ECa}$ ratio on soil surface are important statements that have an obvious equilibrium with the relative values of $\mathrm{Mg}$ and $\mathrm{Ca}$ in soil solution. For instance, Dontsova and Norton (2001) found highly significant linear relationship between $\mathrm{Ca}$ ion percentage on the clay surface and that in soil solution. Also, Vyshpolskyetal(2008) revealed that using irrigation water contains $\mathrm{Mg}^{2+}$ at levels higher than $\mathrm{Ca}^{2+}$ changed their exchangeable ratio on soil, resulting in its degradation and require adequate quantities of $\mathrm{Ca}^{2+}$ to be mitigated. The cation selectivity on soil exchange complexes has been influenced by ion size, valence and hydration radius (Abdouetal, 2000) and the amount of exchangeable $\mathrm{Ca}$ decreased while that of exchangeable $\mathrm{Mg}$ increased as the $\mathrm{Ca} / \mathrm{Mg}$ ratio in the leaching water was decreased (Abdul Ghafoor etal,1990). Also , Karimovetal (2009) reported that higher concentrations of $\mathrm{Mg}^{2+}$ in the irrigation water in comparison to $\mathrm{Ca}^{2+}$ led to replacement of $\mathrm{Na}^{+}$ by $\mathrm{Mg}^{2+}$ on the cation exchange complex resulting in poor soil physical and chemical properties.

There is a lack of studies on the relation between soluble $\mathrm{Mg}$ vs. exchangeable $\mathrm{Mg}$ in soils. The estimations of the soluble cationsare easier than that of the exchangeable cations. Therefore, this study aims to derive proper empirical equations represent the relationship between $\mathrm{SMgP}$ vs. $\mathrm{EMgP}$ and $\mathrm{SMg} / \mathrm{SCa}$ vs. $\mathrm{EMg} / \mathrm{ECa}$ to identify the $\mathrm{Mg}$-soils directly from the soluble cations.

\section{Materials and methods:-}

Ninety soil samples from Kafr El-Sheikh, El-Hamoul, Borollus, Motobus and El-Mahalla El-kobraDistricts represent non saline- , medium saline- and high saline- soils werecollected during winter season (2015/2016) to be used for this study (Map, 1). The collected soil samples were air-dried, ground and sieved through a $2 \mathrm{~mm}$ sieve. The soluble ions, CEC and the exchangeable cations were determined using the methods described by Richards (1954), Jackson (1973) and Page (1982) as shown in Table (1).

$\mathrm{SMgP}$ (soluble Mg*100/total soluble cations), EMgP(exchangeable $\mathrm{Mg} * 100 / \mathrm{CEC}), \mathrm{SMg} / \mathrm{SCa}$ and EMg/ECaratios were calculated. 


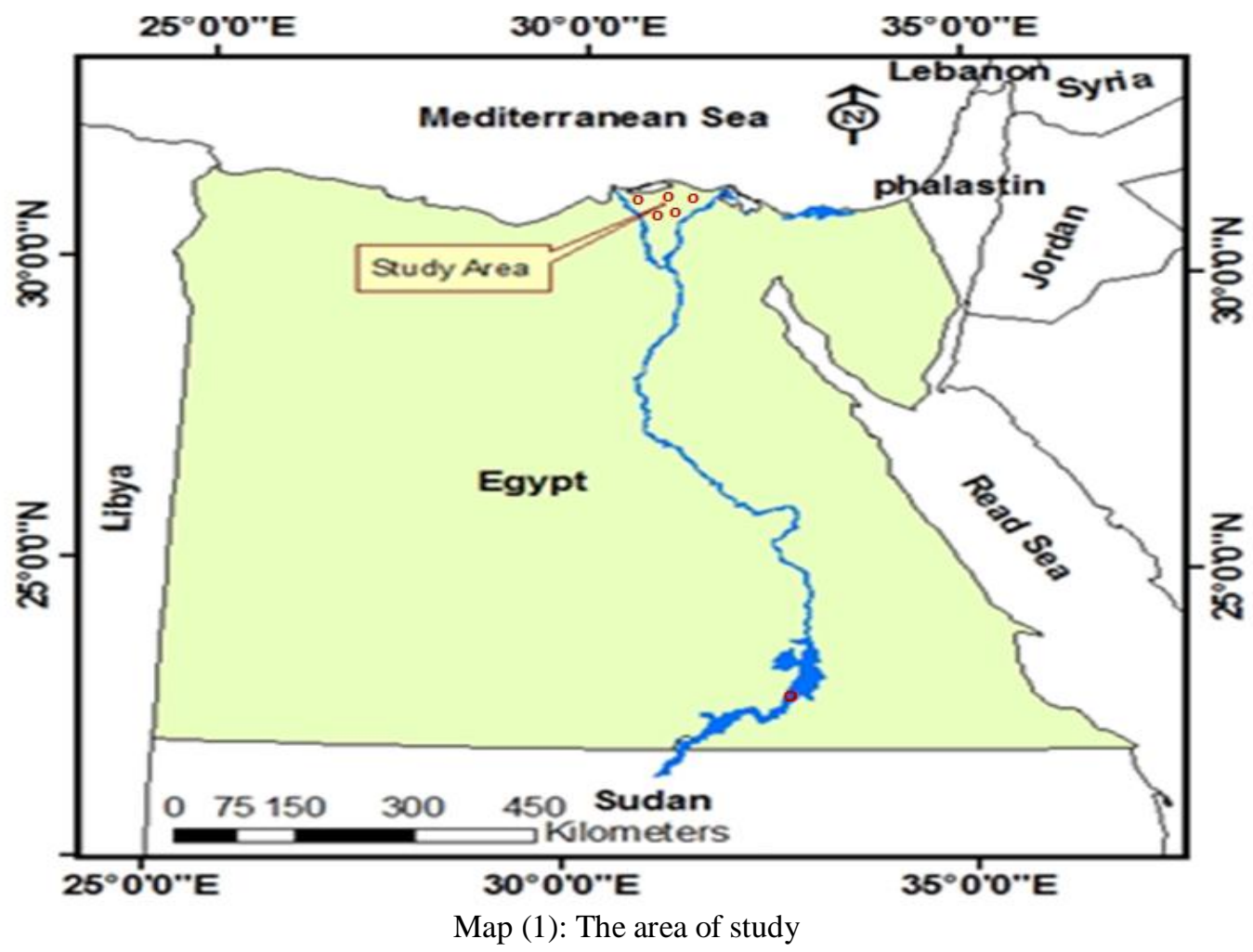

Table 1:- Some physical and chemical properties of the selected soils.

\begin{tabular}{|l|c|c|c|c|c|c|c|c|c|c|}
\hline \multicolumn{1}{|c|}{ Location } & $\begin{array}{c}\text { EC } \\
\mathrm{dS} / \mathrm{m}\end{array}$ & $\begin{array}{c}\text { Clay } \\
\%\end{array}$ & $\begin{array}{c}\text { Silt } \\
\%\end{array}$ & $\begin{array}{c}\text { Sand } \\
\%\end{array}$ & Texture & $\begin{array}{c}\text { CEC(meq } \\
/ 100 \mathrm{~g})\end{array}$ & $\begin{array}{c}\text { SMgP } \\
\text { EMgP }\end{array}$ & $\begin{array}{c}\text { SMg/ } \\
\mathrm{Ca}\end{array}$ & $\begin{array}{c}\text { EMg/ } \\
\mathrm{Ca}\end{array}$ \\
\hline Kafrelsheikh & $2.5-12$ & $38-58$ & $19-24$ & $22-31$ & Clayey & $25-46$ & $9-31$ & $20-40$ & $0.2-3.1$ & $0.5-1.8$ \\
\hline El-Hamoul & $8.0-25$ & $58-64$ & $17-21$ & $19-25$ & Clayey & $29-50$ & $15-36$ & $38-50$ & $0.6-3.5$ & $0.6-2.4$ \\
\hline Borollus & $1.4-1.8$ & $10-15$ & $11-15$ & $70-75$ & Sandy & $5-8$ & $11-30$ & $10-29$ & $0.4-0.7$ & $0.2-0.5$ \\
\hline Motobus & $42-100$ & $60-62$ & $17-19$ & $18-19$ & Clayey & $29-40$ & $10-33$ & $44-59$ & $1.2-2.3$ & $1.6-2.5$ \\
\hline El-Mahalla & $6.5-11.5$ & $53-55$ & $25-29$ & $20-25$ & Clayey & $40-46$ & $14-27$ & $21-35$ & $0.9-1.0$ & $0.7-0.9$ \\
\hline
\end{tabular}

Least squares method was applied to derive proper relationships between $\mathrm{SMgP}$ vs. $\mathrm{EMgP}$ and $\mathrm{SMg} / \mathrm{SCa}$ vs. $\mathrm{EMg} / \mathrm{ECa}$ according to Pindyck andRubinfeld (1976) and Johnston (1972). Also, the statistical comparison measurements with coefficient of determination $\left(\mathrm{R}^{2}\right)$, simple correlation coefficient $(r)$ and t-test were used to compare the relationship between the predicted values calculated by these equations and their actual values.

\section{Results:-}

The characterization of rich-magnesium soils requires estimation of the exchangeable magnesium percentage $(\mathrm{EMgP})$ and/or the exchangeable magnesium to exchangeable calcium ratio $(\mathrm{EMg} / \mathrm{ECa})$. Three empirical equations were derived to represent the relationship between $\mathrm{SMg} / \mathrm{SCa}$ vs. $\mathrm{EMg} / \mathrm{ECa}$ and $\mathrm{SMgP}$ vs. $\mathrm{EMgP}$ to identify the $\mathrm{Mg}$ soils directly from the soluble cations.

Relationship between $S M g / S C a$ vs. EMg/ECa:-

The obtained analysis of soil samples under this study was used to create equation represent the relation between $\mathrm{SMg} / \mathrm{SCa}$ ratio in soil solution and their exchangeable ratio $(\mathrm{EMg} / \mathrm{ECa})$ as shown in equation (1) and Fig (1).

$$
E M g / E C a=-0.245+1.362(S M g / S C a)-0.246(S M g / S C a)^{2}\left(\mathrm{R}^{2}=0.858\right)
$$




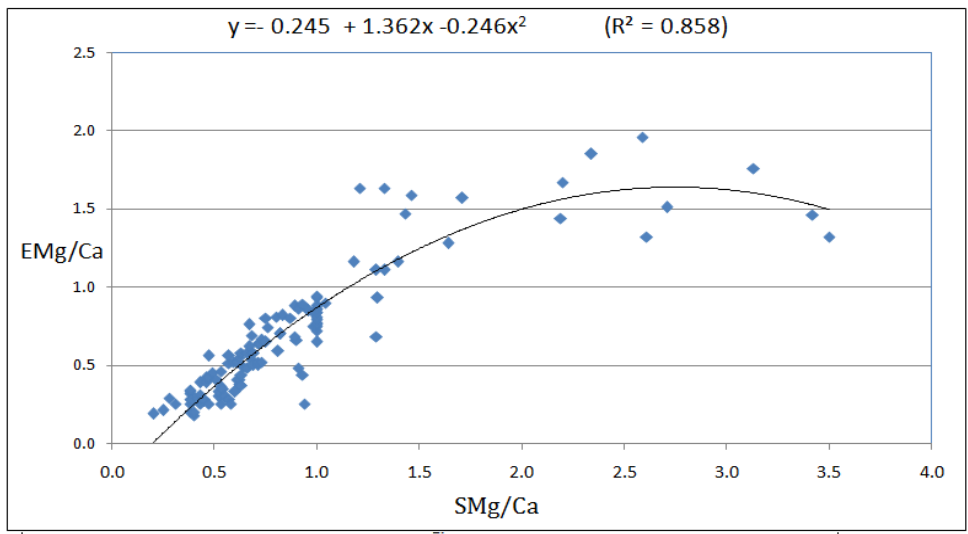

Fig 1:- Relationship between $\mathrm{SMg} / \mathrm{SCa}$ in soil solution vs. $\mathrm{EMg} / \mathrm{ECa}$ on soil surface.

The results showed an obvious positive quadratic relationship between the soluble $\mathrm{Mg} / \mathrm{Ca}$ ratio in soil solution $(\mathrm{SMg} / \mathrm{SCa})$ and that on the exchange sites $(\mathrm{EMg} / \mathrm{ECa})$ in soil samples $\left(\mathrm{R}^{2}=0.858\right)$. The upward gradient of the relation's curve was higher with $\mathrm{SMg} / \mathrm{SCa}$ in soil solution below unity.

Also, the basic data of soil analysis in this study indicated that $\mathrm{Mg} / \mathrm{Ca}$ ratios in soil solution were higher than their exchangeable ratios ( 0.89 and 0.68 , respectively). In the contrary, $\mathrm{Ca} / \mathrm{Mg}$ ratio in soil solution was lower than that on the soil exchange complexes (1.54 and 2.08, respectively) for all $\mathrm{Mg} / \mathrm{Ca}$ ratios in soil solution (Table, 2).

Table 2:- Effect of $\mathrm{Mg} / \mathrm{Ca}$ and $\mathrm{Ca} / \mathrm{Mg}$ ratios in soil solution on their exchangeable values.

\begin{tabular}{|c|c|c|c|c|c|}
\hline \multirow{2}{*}{$\begin{array}{c}\text { Mg/Ca limits } \\
\text { in soil solution }\end{array}$} & \multicolumn{2}{|c|}{ Mg/Ca ratio } & \multirow{2}{*}{$\begin{array}{c}\text { Ca / Mg limits } \\
\text { in soil solution }\end{array}$} & \multicolumn{2}{c|}{ Ca/Mg ratio } \\
\cline { 2 - 3 } \cline { 5 - 6 } & Soluble & Exch. & Soluble & Exch. \\
\hline$<1$ & 0.60 & 0.46 & $<1$ & 0.58 & 0.75 \\
\hline 1.0 & 1.00 & 0.82 & 1.0 & 1.00 & 1.23 \\
\hline$>1$ & 2.00 & 1.41 & $>1$ & 1.90 & 2.60 \\
\hline $0.2-3.5$ (overall) & 0.89 & 0.68 & $0.3-5.0$ (overall) & 1.54 & 2.08 \\
\hline
\end{tabular}

\section{Relationship between SMgP vs. EMgP:-}

The data of soil analysis were used to derive equations represent the relation between soluble magnesium percentage in soil solution $(\mathrm{SMgP})$ and its exchangeable percentage $(\mathrm{EMgP})$ as shown in equation (2) and Fig (2).

$E M g P=-9.298+2.191(S M g P)-0.032(S M g P)^{2} \quad\left(\mathrm{R}^{2}=0.817\right) \ldots \ldots . .(2)$

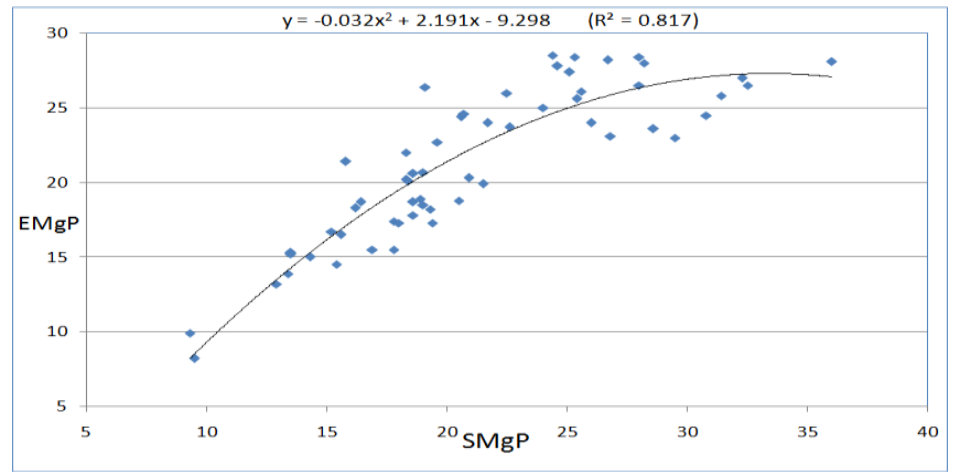

Fig2:- Relationship between $S M g P$ in soil solution vs. $E M g P$ on soil surface.

In this study, a highly significant positive quadratic relationship was observed between SMgP and EMgP, especially with the concentration of $\mathrm{Mg}$ in soil solution below $20 \%$ as shown in Fig (2). Also, this relation showed that EMgP was slightly lower than $\mathrm{SMgP}$, especially when $\mathrm{SMgP}$ value was above $20 \%$. 


\section{Relationship between $S M g P$ vs. EMgP with arcsine transformation:-}

The using of the arcsine transformation instead of the original values of soluble and exchangeable $\mathrm{Mg}$ gave a proper powerful relationship as shown in equation (3) and Fig (3). The determination coefficient $\left(\mathrm{R}^{2}\right)$ was increased from 0.817 in equation (2) to 0.830 in equation (3).

$$
E M g P=-0.432+3.098\left(\operatorname{ASIN}(\operatorname{SQRT}(\operatorname{SMgP} / 100))-2.438(\operatorname{SQRT}(\operatorname{SMgP} / 100))^{2}\left(\mathrm{R}^{2}=0.830\right) \ldots\right.
$$

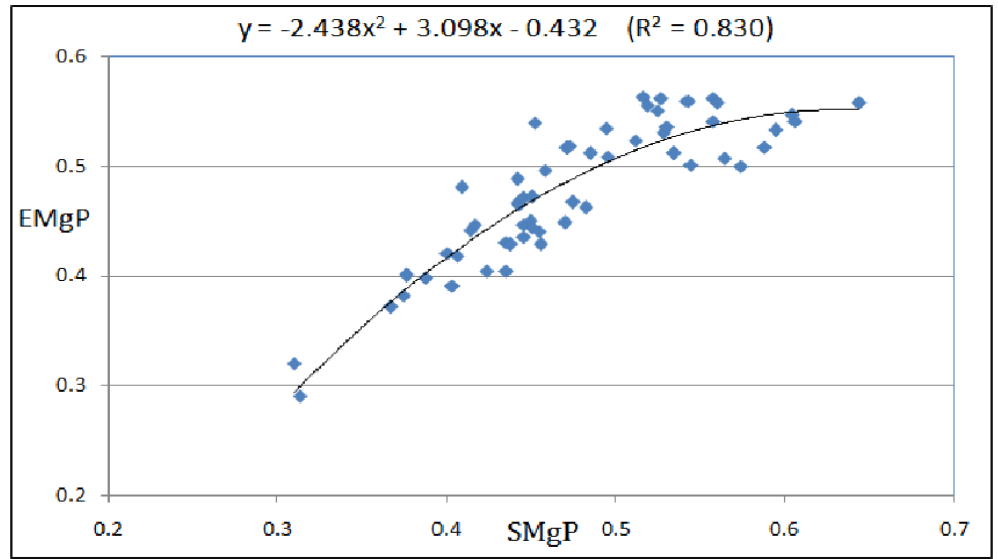

Fig 3:- Relationship between $A S I N(S Q R T(S M g P) / 100))$ in soil solution vs. (SQRT $(E M g P) / 100))$ on soil surface.

In addition, the statistical comparison measurements with coefficient of determination $\left(\mathrm{R}^{2}\right)$, simple correlation coefficient ( $r$ ) and t-test were used to compare the relationship between the predicted values calculated by these equations and their actual values.

The statistical comparison measurements indicated that the quadratic equation (1) is strongly satisfied since the predicted $\mathrm{EMg} / \mathrm{ECa}$ ratios that calculated by this equation are strongly correlated to the actual values $(r>0.92)$ with insignificant difference between them according to t-test. However, the statistical analysis revealed that equation (3) with the transformed data is relatively proper than equation (2) since the predicted $\mathrm{EMgP}$ values that calculated by this equation are strongly correlated to the corresponding actual values $(r>0.91)$ with insignificant difference between them according to t-test.as shown in Table (3).

Table 3:- Statistical measurements to compare the actual values with the predicted values using the empirical equations.

\begin{tabular}{|l|c|c|c|c|}
\hline \multicolumn{1}{|c|}{ Equation } & $\mathrm{R}^{2}$ & $\mathrm{r}$ & \multicolumn{2}{c|}{ t-test } \\
\cline { 2 - 5 } & value & value & t-value & Significance \\
\hline 1-SMg/SCa vs. EMg/ECa & 0.85 .5 & 0.927 & 0.076 & 0.991 \\
\hline 2-SMgP vs. EMgP & 0.817 & 0.904 & 1.342 & 0.676 \\
\hline 3-SMgP vs. EMgP (Trans.) & 0.830 & 0.911 & 0.070 & 0.998 \\
\hline
\end{tabular}

\section{Discussions:-}

The results showed that the upward gradient of the relation's curve between $\mathrm{SMg} / \mathrm{SCa}$ and $\mathrm{EMg} / \mathrm{ECa}$ was higher with $\mathrm{SMg} / \mathrm{SCa}$ in soil solution below unity, indicating that $\mathrm{Ca}$ is more preferable than $\mathrm{Mg}$ over this limit. Also, the $\mathrm{SMg} / \mathrm{SCa}$ ratios were higher than $\mathrm{EMg} / \mathrm{ECa}$ ratios $(0.89$ and 0.68 , respectively). In the contrary, $\mathrm{SCa} / \mathrm{SMg}$ ratio was lower than $\mathrm{SCa} / \mathrm{SMg}$ (1.54 and 2.08, respectively) for all $\mathrm{Mg} / \mathrm{Ca}$ ratios in soil solution. This indicated a preference for $\mathrm{Ca}$ in all studied soil samples. Curtin et al. (1994) explained the difference in behavior between $\mathrm{Ca}$ and $\mathrm{Mg}$ as due to that the hydrated radius of the $\mathrm{Mg}^{++}$ion is slightly greater than that of $\mathrm{Ca}^{++}$ion $(0.47 \mathrm{vs} .0 .42 \mathrm{~nm}$, respectively) and consequently lower electrostatic force with which a hydrated $\mathrm{Mg}^{++}$ion is held at the clay surface.

The trend test results showed highly significant positive relation was observed between SMgP and EMgP, especially with $\mathrm{SMgP}$ below $20 \%$, while, $\mathrm{EMgP}$ was slightly lower than $\mathrm{SMgP}$, especially when SMgP value was above $20 \%$. Fisher, Madeline (2011) explained the slight difference between soluble and exchangeable $\mathrm{Mg}$ as due to the ability of different cations to held at the soil surface can be arranged as: $\mathrm{Ca}>\mathrm{Mg}>\mathrm{K}>\mathrm{Na}$ with relative holding power of 
$43,27,1.7$ and 1 ,respectively. This indicates that the ratio of the exchangeable portion comparing to the soluble portion is strongly higher with $\mathrm{Ca}$, slightly lower with $\mathrm{Mg}$ and strongly lower with both $\mathrm{K}$ and $\mathrm{Na}$.

The using of the arcsine transformation of soluble and exchangeable $\mathrm{Mg}$ gave a proper powerful relationship. The $S M g P$ vs. $E M g P$ were used after arcsinetransformation to give a gaussiandistribution and develop the relation according toIsaaks and Srivastava (1989), so, the determination coefficient $\left(\mathrm{R}^{2}\right)$ was increased from 0.817 to 0.830 .

The statistical comparison measurements indicated that the quadratic equation using the original data is strongly satisfied since the predicted EMg/ECa ratios that calculated by this equation are strongly correlated to the actual values ( $r>0.927$ ) with insignificant difference between them according to t-test. Also, the statistical analysis revealed that the arcsinetransformed data is relatively proper since the predicted EMgP values that calculated by this equation are strongly correlated to the corresponding actual values more than that with the untransformed data $(\mathrm{r}=0.911$ and 0.904 , respectively) with lower t value.

\section{Conclusion:-}

It could be concluded that the exchangeable $\mathrm{Mg}^{++}$as well as its relation to $\mathrm{Ca}^{++}$on soil surface can be easily predicted using their corresponding values in soil solution. However, additional studies have to be in our interesting tostrengthen these relations to be safely used in identifying the rich-Mg soils.

\section{References:-}

1. Abdou FM, El-Gundy MM, and Khidr MH. 2000. Selective adsorption of Ca and Mg on some exchangers .Egypt. J. Soil Sci. 1-2:75-88.DOI 10.1007/s12517-010-0262-7.

2. Abdul GhafoorF, and Abdullah M.1990. USE OF High magnesium brackish water for reclamation of salinesodicsoil.1.Soil Improvement. Pak. J. Agri. Sci., 27(4):394. DOI: 1.054

3. Agar AI. 2012. Improvement of exchangeable Ca:Mg ratio by using gypsum and waste of sulfur in magnesiumaffected soils. Afr. J. Agric. Res., 7(14):2205-2214.DOI: 10.5897/AJAR2016.10957[Article Number: 215192959102]

4. Ansari MA, Kumar SA, Subbarayappa CT, and Sudhir K. 2010. Effect of Calcium-Magnesium Ratios in an Alfisol on Growth and Yield of Finger Millet in a Red Sandy Clay Loam soil. Mysore J. Agric. Sci., 44(4): 735741.DOI:10.1104/pp.103.033027.

5. Bardhan G, ChaudharI SK, and Mohapatra PK. 2007. Effect of Irrigation Water Quality on Saturated Hydraulic Conductivity of TypicHaplustert, VerticHaplustept, and Lithic Ustorthent,Soil J. Agric. Phys., 7: 38-46.DOI $: 10.1111$

6. Bohn HL, McNeal BL, and O.Conner GA. 1985. Soil chemistry .John Wiley \&Sons,Inc, New York.DOI: 10.1002/9780470431771

7. Curtin D, Steppuhn H, and Selles F. 1994.Effect of magnesium on cation selectivity and structural stability of sodic soils .Soil Sci. Soc.Am. J., 58 :730-737.DOI: 10.1080/01431168408948839

8. DontsovaK, and Norton LD. 2001. Effects of Exchangeable Ca:Mg Ratio on Soil Clay Flocculation, Infiltration and Erosion. In: D.E. Stott, R.H. Mohtar and G.C. Steinhardt (eds). 2001. Selected papers from the 10th International Soil Conservation Organization Meeting, May 24-29, 1999 at Purdue Univ. and the USDA-ARS National Soil Erosion Research Laboratory, :580-585.DOI:10.1007/s11027-012-9411

9. DontsovaKM, and Norton LD. 2002. Clay dispersion, infiltration and erosion as influenced by exchangeable Ca and Mg. Soil Sci., 167: 1-1 0.DOI: 10.1097/00010694-195988030-00003.

10. Fisher, Madeline 2011. Amending soils with Gypsum. Crops \& Soils magazine, Nov.-Dec. 2011, American Soc. of Agron..mfisher@sciencesocieties.org . DOI: 10.1016/0378-3774(83)90033-1

11. Garcia-a-Ocampo A. 2003. Physical properties of Magnesium affected Soils in Colombia .Lecture given at the National Univ. of Colombia,Palmira College on Soil Physics Trieste: 3-21, March 2003, LNS 0418016.DOI:10.1063/1.3680558

12. IssaksA, and Srivastava RM.1989. An introduction into applied geostatistics. Oxford University Press, New York.DOI:10.1017/ CBO9780511809170

13. Jackson ML. 1967. Soil Chemical Analysis Advanced course.Puble.By the author, Dept. of Soils, Univ. of Wise. Madison 6, Wishensin, USA.Doi: 10.1016/j

14. Johnston J. 1972. Economic Methods.McGraw-Hill Kogakusha,Ltd,Tokyo.DOI:10.1007/BF02987526

15. Karimov HA,Qadir M, Noble A, Vyshpolsky F, Anzelm K. 2009. Development of Magnesium-Dominant Soils 
under Irrigated Agriculture in Southern Kazakhstan. Project supported by the Asian Development Bank (RETA 6208).DOI:org/10.1787/eco

16. Norton LD, and Dontsova KM. 1998. Use of soil amendments to prevent soil surface sealing and control erosion .Advances in GeoEcology, (31):581-587.DOI: 10.1525/aa.2005.107.1.062

17. Page AL. 1982. Methods of Soil Analysis. Part 1: Physical properties and part 2: Chemical and microbiological properties. (3nd ed.) Amer. Soc. Agron., In Soil Sci. Soc. Amer. Inc., Madison, Wisconsin, USA.DOI:10.1017/S0021859600002598

18. Pindyck RS, and Rubinfeld DL.1976. Economic Models and Economic Forecasts. McGraw -Hill Kogakusha, Ltd, Tokyo.DOI: $10.1063 / 1.335846$

19. Richards LA. 1954. Diagnosis and improvement of saline and alkaline soil. USDA. Handbook No. 60.Doi: 10.1016/j.agwat.2007.05.010

20. Shainberg I, Alperovitch N, and Keren R. 1988. Effect of management on the hydraulic conductivity of Nasemectite-sand mixtures. Clays and Clay Minerals, 36 (5): 432-438.DOI Impact Factor: 1.398

21. Tanji KK. 1990. Agricultural Salinity Assessment and Management ASCE Manuals and Reported on Engineering Practice No. p.71.DOI: 10.3906/tar-1412-106

22. Vyshpolsky F, Qadir M, Karimov A, Mukhamedjanov K, Bekbaev U, Paroda R, Aw-Hassan A, and Karajeh F. 2008. Enhancing the productivity of high-magnesium soil and water resources in Central Asia through the application of phosphor-gypsum .L and Degradation \& Development, 19 (Issue 1): 45-56.DOI: 10.1002/ldr.696.

23. Vyshpolsky F, Bekbaev U, MukhamedjanovKh, Ibatullin S, Paroda R, Yuldashev T, Karimov A, Aw-Hassan A, Noble A, and Qadir M. 2015. Enhancing the Productivity of High-Magnesium Soil and Water Resources. International Water Management Institute (IWMI).publications.iwmi.org/pdf/H040657.DOI.org/10.5337/2010.234.

24. Zhang XC, and Norton DL. 2002. Effect of exchangeable Mg on saturated hydraulic conductivity, disaggregation and clay dispersion of disturbed soils. J. Hydrolo., 260 (1-4):194-205.DOI Compact Factor: 1.226. 